\title{
A Case of Primary Hepatic Extranodal Marginal Zone B-Cell Lymphoma of Mucosa-Associated Lymphoid Tissue (MALT) Type Treated by Radiofrequency Ablation (RFA) and Literature Review
}

\section{Zhe Xu}

The Second Hospital of Dalian Medical University

\section{Chong Pang}

The Second Hospital of Dalian Medical University

\section{Jidong Sui}

The Second Hospital of Dalian Medical University

Zhenming Gao ( $\nabla$ gaozhenmingdy2y@163.com )

The Second Hospital of Dalian Medical University https://orcid.org/0000-0003-0647-1121

\section{Case report}

Keywords: primary hepatic lymphoma, MALT lymphoma, marginal zone B-cell lymphoma, RFA, 18F-FDG $\mathrm{PET} / \mathrm{CT}$

Posted Date: December 4th, 2020

DOI: https://doi.org/10.21203/rs.3.rs-117745/v1

License: (c) (1) This work is licensed under a Creative Commons Attribution 4.0 International License. Read Full License 


\section{Abstract}

\section{Background}

Primary hepatic mucosa-associated lymphoid tissue (MALT) lymphoma is an extremely rare liver malignancy and is usually lack characteristic imaging findings, which is often misdiagnosed.

\section{Case presentation}

The present study reports a case of a 63-year-old woman diagnosed with primary hepatic extranodal marginal zone B-cell lymphoma of MALT type. The patient received the needle biopsy and radiofrequency ablation and has not shown relapse up for the following 12 months.

\section{Conclusions}

This case is reported for its rarity and the treatment for this patient is unique and effective. Our case provides a new option for the treatment of hepatic MALT lymphoma. We also present our findings from a systematic review to improve our current understanding of the disease.

\section{Background}

Primary hepatic lymphoma $(\mathrm{PHL})$ is a rare disease that accounts for only $0.1 \%$ of liver malignancies, $0.4 \%$ of extranodal lymphomas, and $0.016 \%$ of non-Hodgkin's lymphomas $(\mathrm{NHL}),{ }^{1,2}$ while primary hepatic marginal zone B-cell lymphoma of mucosa-associated lymphoid tissue (MALT) type is reported to occur in only $3 \%$ of $\mathrm{PHL} .{ }^{3}$ Marginal zone B-cell malignant lymphoma refers to a low-grade malignant nonHodgkin lymphoma that occurs in MALT. The concept of MALT lymphoma was first proposed by Isaacson and Wright in 1983 to describe extranodal malignant lymphoma of marginal zone B-cell origin. ${ }^{4}$ MALT lymphoma can involve the gastrointestinal tract, salivary gland, conjunctiva, thyroid, lung, breast, and liver. ${ }^{5}$ Primary hepatic MALT lymphoma is extremely rare, while there are also few reports on their clinical characteristics and the best treatment methods. Increasing early recognition of hepatic MALT lymphomas can avoid unnecessary liver resection or reduce the scope of liver resection if preoperative chemotherapy is responsive. ${ }^{6}$ Herein, we report a case of primary hepatic MALT lymphoma. Meanwhile, we also review the relevant literatures to improve more detailed cognition of primary hepatic MALT lymphoma.

\section{Case Presentation}

A 63-year-old woman was admitted to hospital following a focal liver mass discovered incidentally in ultrasonography. The patient was reported no symptoms, other than upper abdominal discomfort. She had no significant medical history and the physical examination was unremarkable without splenomegaly or superficial lymph node swellings. Findings for all clinical laboratory parameters, including blood routine examination, hepatic and renal function, lactic dehydrogenase (LDH), alpha 
fetoprotein (AFP), carcinoembryonic antigen (CEA) and carbohydrate antigen 19 - 9 (CA19-9), were within the normal range. No hepatitis $B$ virus (HBV), hepatitis $C$ virus $(\mathrm{HCV})$, or human immunodeficiency virus infection was found. There was no abnormality in rheumatic and immunity index. In addition, no helicobacter pylori (HP) infection and no tumor was observed by upper gastrointestinal endoscope.

Abdominal ultrasound examination showed a hypoechoic liver mass in the segment $\mathrm{VI}$ (S6). Enhanced magnetic resonance imaging (MRI) showed a $1.6 \times 1.7 \mathrm{~cm}$ solitary mass with T1 hypointensity and T2 hyperintensity (Fig. 1a). The mass was enhanced in arterial phase and washed out in portal phase (Fig. 1b, c). The lesion showed low signal in hepatocyte specific phase (Fig. 1d). No extrahepatic mass was discovered by the MRI. Contrast-enhanced ultrasonography (CEUS) showed that the nodular lesion had mild inhomogeneous hyperenhancement in the arterial phase and wash-out in the portal phase (Fig. 1e, f). Based on the results of imaging examination, we suspected the tumor as a hepatocellular carcinoma. According to Guidelines for diagnosis and treatment of primary liver cancer in China (2019 edition), when the tumor is less than $2 \mathrm{~cm}$, the tumor-free survival rate and overall survival rate of RFA are similar to surgical resection, but the incidence of complications and length of hospital stay are lower than surgical resection. The patient consented to receive the needle biopsy and radiofrequency ablation (RFA). Histologic analysis of the liver biopsy revealed a large number of single form lymphocytes and a few plasma cells infiltrating the hepatic lobule, the manifestations of lymphoepithelial lesions and lymphocytes penetrating the hepatocytes were observed. Immunohistochemistry findings were positive for CD20 and BCL-2, whereas negative for CD3, CD5, CD10, CD23, CD43, BCL-6 and Cyclin D1. Ki-67 labeling index was about $5 \%$ (Fig. 2). According to the pathological findings, the patient was diagnosed with primary hepatic extranodal marginal zone B-cell lymphoma of MALT type. The patient's disease was classified as Ann Arbor stage IE and no additional treatment was performed while close follow-up was recommended. Computed tomography (CT) scan of the abdomen after operation showed effective results of ablation position (Fig. 3a). The patient performed fluorine-18-fluorodeoxyglucose positron emission tomography/computed tomography (18F-FDG PET/CT) after discharge, and no signs of abnormally high metabolic tumor were found. No abnormal indicators were found in the blood routine examination and liver biochemistry examination of the patient every 3 months. No abnormal MRI findings were found in this patient one year after operation (Fig. 3b, c, d). The patient remains well and has not shown relapse up for the following 12 months.

\section{Discussion}

MALT lymphoma is a low-grade B-cell lymphoma, among which HP-related gastric MALT lymphoma is the most common. At present, there are relatively recognized unified standards for the diagnosis and treatment of gastric MALT lymphoma. However, primary hepatic MALT lymphoma is extremely rare, its etiology, clinical characteristics and best treatment methods have not yet been clarified. Therefore, we summarize and study our case and combine with the reported literatures to improve the understanding of the disease and enrich clinical evidence for future diagnosis and treatment. 
We searched case reports of hepatic MALT lymphoma through PubMed and performed reading analysis. When the disease was confined to the liver and there was no evidence of extrahepatic invasion, we believed that the hepatic lymphoma was primary and included in the statistics. According to statistics, we found 66 reports, ${ }^{5,7-71}$ including this case, a total of 110 cases of primary hepatic MALT lymphoma, of which 79 cases had relatively detailed clinical data (Table 1). Among them, 42 cases were male (38\%), 45 cases were female (41\%), with an age ranging from 30 to 89 years and a median age of 63.5 years. Most patients $(57.3 \%)$ were asymptomatic, and most cases $(68.2 \%)$ had a single tumor with a diameter ranging from $0.7 \mathrm{~cm}$ to $20 \mathrm{~cm}$.

MALT lymphoma usually develops in chronic inflammation accompanied by infectious pathogens, such as HP-related chronic gastritis and autoimmune diseases. Nevertheless, the cause of primary hepatic MALT lymphoma is not fully understood. Some studies revealed that the HCV infection rate in PHL patients was $9-42 \%,{ }^{72-74}$ while the HBV infection rate was even as high as $60 \% .{ }^{75}$ Interestingly, being infected with HBV/HCV would not affect the chemotherapy results and prognosis of PHL patients. ${ }^{12}$ Some scholars believe the continuous inflammatory stimulation may induce the occurrence of the disease. ${ }^{5}$ In previous case reports, primary hepatic MALT lymphoma was considered to be related to primary biliary cirrhosis (PBC) ${ }^{54} \mathrm{HCV}_{1}{ }^{19,72,76,77} \mathrm{HBV}^{48,62} \mathrm{HP}$ infection, ${ }^{31}$ and non-alcoholic steatohepatitis $(\mathrm{NASH}),{ }^{27}$ etc. Meanwhile, some literatures indicated that it might be related to Epstein-Barr virus, which induced polyclonal B-cell proliferation to lead to lymphoma. ${ }^{78}$ However, a meta-analysis involving approximately 16,300 patients with PBC did not find a significant correlation between PBC and NHL. ${ }^{79}$ In the literature review, there were 21 cases (19.1\%) of HBV infection and 16 cases (14.5\%) of HCV infection, while there were 8 cases of PBC (7.3\%), 2 cases of autoimmune hepatitis (1.8\%), and 12 cases of HP infection (10.9\%). In our case, the patient has no history of HBV, HCV, autoimmune disease, or HP infection. Due to the rarity of disease, the exact role of related risk factors in the occurrence of primary hepatic MALT lymphoma needs further investigation.

Patients with PHL usually have elevated LDH. ${ }^{51,78}$ It has been reported that $L D H$ is a more recognized lymphoid tumor marker. ${ }^{80}$ Page et al. consider that when the elevated LDH level exceeds $10 \%$ of the normal standard, the risk of disease recurrence in such patients increases. ${ }^{51}$ The elevated level of LDH in patients with PHL is positively correlated with the degree of tumor malignancy, which can be used as an auxiliary index to judge the prognosis. ${ }^{81}$ Relevant literature shows that tumor markers in hepatic MALT lymphoma, including AFP, CA19-9, CEA, etc., are often within the normal range. ${ }^{50}$ Therefore, any patient with liver mass whose LDH is elevated, AFP and CEA are normal, should be considered whether there is the possibility of hepatic MALT lymphoma. This can be regarded as a valuable biological feature.

The signal intensity analysis of PHL lesions showed no significant difference in unenhanced or enhanced images. Some literature summarizes that PHL usually manifests as hypoechoic changes under ultrasound. In MRI, PHL usually shows low or iso-signal T1 and high-signal T2. ${ }^{2}$ After the administration of contrast medium, about $50 \%$ of the cases showed a lower density of the lesions in the arterial phase and the delayed phase. ${ }^{82}$ Meanwhile, $30 \%$ of cases showed patchy enhancement and $15 \%$ of cases were 
ring-like enhancement. ${ }^{10}$ All cases showed low signal during hepatobiliary phase. However, more than $90 \%$ of the PHL cases were diffuse large B-cell lymphoma (DLBCL), so far, there is still no characteristic description of hepatic MALT lymphoma imaging. Dong et al. consider that when liver tumors have no obvious space-occupying effect in CT imaging, and the blood vessels and bile ducts in the liver are running normally, the possibility of hepatic MALT lymphoma should not be excluded. ${ }^{20}$ In our literature review, there are 35 more complete MRI descriptions. Almost all cases showed T1 low signal and T2 high signal, but there was no regular performance in the arterial and portal phase. CEUS guidelines suggest that CEUS can distinguish hepatocellular carcinoma and other lesions (such as regenerative nodules), as well as benign and malignant lesions. It also helps in the differential diagnosis of rare liver tumors. ${ }^{83}$ However, due to the small number of related cases, the guidelines did not mention the imaging findings of primary hepatic MALT lymphoma. According to our statistics, 5 cases of primary hepatic MALT lymphoma were diagnosed and analyzed by CEUS ( 4 cases are described in detail), and 2 of them showed uneven enhancement in the arterial phase and uneven regression in the portal phase. ${ }^{22}$ Our case showed the same performance. The other 2 cases showed uniform wash-in and wash-out in the arterial and portal phase respectively, showing more prone to hepatocellular carcinoma. ${ }^{23,59}$ However, it is not very typical to see uneven enhancement in the arterial phase of hepatocellular carcinoma. Therefore, when the tumor shows uneven wash-in and wash-out in the arterial and portal phase, we should include hepatic MALT lymphoma among the diseases that require differential diagnosis. Meanwhile, Shiozawa et al. consider that the feature of no blood vessel penetrating the tumor may distinguish primary hepatic MALT lymphoma from other malignant lymphomas. Compared with dynamic CT and MRI, CEUS can evaluate intratumoral hemodynamics in real time, which is easier and more accurate to see penetrating blood vessels. ${ }^{59}$ Although there is no specific imaging of primary hepatic MALT lymphoma, the rare sharpness and irregularity of the lesion edge on ultrasound examination may be more prone to lymphoma, and it is worth performing a local biopsy to clarify the nature. ${ }^{22}$

The role of 18F-FDG PET/CT in the detection rate, diagnosis and follow-up of extragastric MALT lymphoma has been controversial. A study analyzed 227 MALT lymphomas, which indicated that the metabolic rate of 18F-FDG was related to the location and general morphological characteristics of the lesion. However, the diagnosis of primary hepatic MALT lymphoma by 18F-FDG PET/CT is not described. ${ }^{84}$ In previous reports, 17 cases of PET-CT were performed, and their hepatic MALT lymphomas all showed high metabolism of $18 \mathrm{~F}-\mathrm{FDG} .7,9,11,17,19,20,29,34,49,61,69,75$ A recent study proposed that the 18FDG metabolic rate of extragastric MALT lymphoma is significantly related to Ki-67 proliferation. ${ }^{85}$ When $\mathrm{Ki}-67>15 \%$, the 18-FDG intake of the lesions was significantly increased, but only 4 cases of related hepatic MALT lymphoma cases were involved. This result still needs to be further studied, but it is still valuable for postoperative prognostic evaluation and follow-up. Significantly, compared with other aggressive lymphomas such as DLBCL, MALT lymphoma has a relatively low FDG uptake intensity, ${ }^{86,87}$ which has more differential significance. Regrettably, our case failed to perform 18F-FDG PET/CT before surgery. The postoperative 18F-FDG PET/CT showed no hypermetabolic lesions. This not only indicates no extrahepatic lesions, but also proves that the result of RFA was very successful. Lugano classification 
proposes that 18F-FDG PET/CT is officially included in the standard staging of FDG-avid lymphoma, which can improve the accuracy of staging and better evaluate the prognosis. ${ }^{88}$ Whether 18F-FDG PET/CT can also be used for early diagnosis, staging, and treatment of hepatic MALT lymphoma, it is still necessary to collect large samples for analysis. However, 18F-FDG PET/CT is still helpful in the diagnosis of primary hepatic MALT lymphoma when there are no high-uptake lesions in other parts of the body. It may become a new method for staging, follow-up and prognostic evaluation in the future.

Most masses are discovered accidentally and lack extrahepatic manifestations, which are often misdiagnosed. Among the retrieved cases, almost all cases could not be clearly diagnosed before pathological diagnosis. Some cases $(21.8 \%)$ were diagnosed as other malignant tumors or even benign tumors before surgery or biopsy. In our case, we initially diagnosed it as hepatocellular carcinoma before surgery. Therefore, the diagnosis of primary hepatic MALT lymphoma still needs pathological biopsy to confirm. Pathological biopsy of primary hepatic MALT lymphoma shows the presence of reactive follicles. The marginal zone cells infiltrate the epithelium, which can cause the formation of lymphoepithelial lesions and lead to the destruction of part of the bile duct structure. Lymphoepithelial lesions of the bile duct are typical manifestations of primary hepatic MALT lymphoma, ${ }^{89}$ which are consistent with our case. Marginal zone B-cell lymphomas are usually positive for CD20 and CD79a, but lack CD5, CD10, CD23, and CD43, and usually express IgM and Bcl-2. Ki67, p53 and Bcl-6 may help distinguish liver marginal zone B-cell lymphoma from DLBCL. Typical liver marginal zone B-cell lymphoma grows inertly, if these markers are diffusely expressed, the mass is closer to DLBCL. ${ }^{89}$ Therefore, proper immunohistochemistry and molecular research are also essential. It is not only to help distinguish lymphoma from other malignant tumors, but also to judge the immunophenotype of lymphoma.

To our knowledge, there is no consensus on the optimal treatment for non-gastric MALT lymphomas. The recommendations of the United States National Comprehensive Cancer Network for non-gastric MALT lymphomas include radiotherapy, surgery, chemotherapy and comprehensive treatment. Because cases of primary hepatic MALT lymphoma are extremely rare, we are unable to design prospective randomized clinical trials to determine the optimal treatment. According to literature statistics, most of the patients (48.2\%) underwent surgical resection or liver transplantation after diagnosis, accompanied by chemotherapy adjuvant therapy, and the postoperative effect was well, and most of them could be cured. However, there were still 2 cases of tumor recurrence during long-term follow-up after surgical resection, ${ }^{25,35}$ suggesting the importance of close follow-up after treatment. Obiorah et al. reported a case of primary hepatic MALT Iymphoma that developed pulmonary MALT lymphoma 1 year after surgical resection, and parotid MALT lymphoma occurred 7 years later. ${ }^{49}$ Chen et al. reported the surgical patient of primary hepatic MALT lymphoma developed pulmonary MALT lymphoma 8 years later. ${ }^{16}$ Both cases provide us with the possibility of future progression of primary hepatic MALT lymphoma. Although the course of the disease usually progresses slowly, ${ }^{90}$ it may relapse after many years and involve other common external nodes. Therefore, we should be alert to the possibility of distant metastasis, and regular follow-up is recommended even after 5 years of surgery. 
As far as we know, only one primary hepatic MALT lymphoma Japanese received RFA treatment before. ${ }^{28}$ In our case, RFA was performed after confirmation of liver malignant tumor. Postoperative imaging results showed that the surgical scope was well. The patient was regularly followed up one year after surgery and no signs of recurrence. Our case indicates that RFA is safe and effective in the treatment of primary hepatic MALT lymphoma in the short run while avoiding unnecessary liver resection. However, long-term follow-up and more relevant cases are still needed to observe the effect of RFA on long-term survival of this disease. As can be seen from our case, when the tumor is confirmed by pathological biopsy, non-resection therapy, such as RFA, can also be selected. Our case provides a new option for the treatment of hepatic MALT lymphoma.

\section{Conclusions}

Based on our case and literatures reported, primary hepatic MALT lymphoma is usually found by chance and has no characteristic imaging manifestations, preoperative diagnosis is still a great challenge. Although there is still no standard treatment and management model for this rare disease, the patients who received surgical, chemotherapy, radiotherapy or antiviral therapy have good efficacy and prognosis. Our case received RFA shows good efficacy of primary hepatic MALT lymphoma. The effect of RFA on long-term survival still needs further follow-up observation. However, due to the small number of cases, the best treatment has not yet been established, more case accumulation and multi-center cooperation are needed to provide more detailed clinical information to supplement and improve our current understanding of the disease.

\section{Abbreviations}




\begin{tabular}{ll}
\hline Primary hepatic lymphoma & $\mathrm{PHL}$ \\
\hline non-Hodgkin's lymphomas & $\mathrm{NHL}$ \\
\hline mucosa-associated lymphoid tissue & $\mathrm{MALT}$ \\
\hline lactic dehydrogenase r & $\mathrm{LDH}$ \\
\hline carcinoembryonic antigen & $\mathrm{CEA}$ \\
\hline carbohydrate antigen 19-9 & $\mathrm{CA} 19-9$ \\
\hline hepatitis B virus & $\mathrm{HBV}$ \\
\hline alpha-fetal protein & $\mathrm{AFP}$ \\
hepatitis C virus & $\mathrm{HCV}$ \\
helicobacter pylori & $\mathrm{HP}$ \\
segment VI & $\mathrm{S} 6$ \\
magnetic resonance imaging & $\mathrm{MRI}$ \\
radiofrequency ablation & $\mathrm{RFA}$ \\
Contrast-enhanced ultrasonography & $\mathrm{CEUS}$ \\
Computed tomography & $\mathrm{CT}$ \\
fluorine-18-fluorodeoxyglucose positron emission tomography/computed & PET/CT \\
tomography & $\mathrm{PBC}$ \\
primary biliary cirrhosis & $\mathrm{NASH}$ \\
non-alcoholic steatohepatitis & \\
\hline
\end{tabular}

\section{Declarations}

\section{Ethics Approval}

Not applicable.

\section{Patient Consent Statement:}

We have got informed consent that the patient has provided for publication of the case.

\section{Declaration of Competing Interest:}

The authors declare no potential conflicts of interest.

\section{Availability of Data and Materials}


All data generated or analysed during this study are included in this published article [and its supplementary information files].

\section{Declaration of Competing Interest:}

The authors declare no potential conflicts of interest.

\section{Funding for the research}

The Funder: National Natural Science Foundation of China;

Award Number:81773966;

Grant Recipient/Corresponding Author: Zhenming Gao

\section{Authors' Contribution}

PC and SJD interpreted the patient data regarding the hematological disease and the transplant. XZ searched the literature, and was a major contributor in writing the manuscript. All authors read and approved the final manuscript.

\section{Acknowledgements}

The authors thank Dr Kun Guo and Dr Deguang Sun for their technical support and for providing the pathologic pictures.

\section{Author information:}

First author. Zhe Xu(1996-),female, postgraduate of the First Department of Hepatobiliary and Pancreatic Surgery, The Second Hospital of Dalian Medical University;

\section{E-mail: drxz12345@163.com}

Second author. Chong Pang(1994-),male, postgraduate of the First Department of Hepatobiliary and Pancreatic Surgery, The Second Hospital of Dalian Medical University

E-mail: pangchong0475@163.com

Third author. Jidong Sui(1988-),male, doctor of the First Department of Hepatobiliary and Pancreatic Surgery, The Second Hospital of Dalian Medical University

E-mail: sui10086@sina.com

Corresponding Author: Zhenming Gao(1972-) male, doctoral supervisor, chief surgeon of the First Department of Hepatobiliary and Pancreatic Surgery, The Second Hospital of Dalian Medical University. 


\section{References}

1. Jaffe ES. Malignant lymphomas: pathology of hepatic involvement. Semin Liver Dis 1987;7(3):25768.

2. Noronha V, Shafi NQ, Obando JA, Kummar S. Primary non-Hodgkin's lymphoma of the liver. Crit Rev Oncol Hematol 2005;53(3):199-207.

3. Lei KI. Primary non-Hodgkin's lymphoma of the liver. Leuk Lymphoma 1998;29(3-4):293-9.

4. Isaacson P, Wright DH. Malignant lymphoma of mucosa-associated lymphoid tissue. A distinctive type of B-cell lymphoma. Cancer 1983;52(8):1410-6.

5. Zucca E, Conconi A, Pedrinis E, et al. Nongastric marginal zone B-cell lymphoma of mucosaassociated lymphoid tissue. Blood 2003;101(7):2489-95.

6. Masood A, Kairouz S, Hudhud KH, Hegazi AZ, Banu A, Gupta NC. Primary non-Hodgkin lymphoma of liver. Curr Oncol 2009;16(4):74-7.

7. Albano D, Giubbini R, Bertagna F. 18F-FDG PET/CT and primary hepatic MALT: a case series. Abdom Radiol (NY) 2016;41(10):1956-9.

8. Ascoli V, Lo Coco F, Artini M, Levrero M, Martelli M, Negro F. Extranodal lymphomas associated with hepatitis C virus infection. Am J Clin Pathol 1998;109(5):600-9.

9. Bao C, Wei J, Zhao X, et al. Prognostic value of fluorine-18-fluorodeoxyglucose positron emission tomography/computed tomography in primary hepatic mucosa-associated lymphoid tissue lymphoma: A case report and review of the literature. Medicine (Baltimore) 2018;97(10):e9877.

10. Betianu Cl, Dima A, Pavaloiu G. Primary hepatic mucosa-associated lymphoid tissue lymphoma in a patient with no chronic liver disease: Case report. Radiol Case Rep 2017;12(4):715-9.

11. Bohlok A, De Grez T, Bouazza F, et al. Primary Hepatic Lymphoma Mimicking a Hepatocellular Carcinoma in a Cirrhotic Patient: Case Report and Systematic Review of the Literature. Case Rep Surg 2018;2018:9183717.

12. Bronowicki J-P, Bineau C, Feugier P, et al. Primary lymphoma of the liver: clinical-pathological features and relationship with HCV infection in French patients. Hepatology 2003;37(4):781-7.

13. Cabassa P, Morone M, Matricardi L. An unusual liver mass. Gastroenterology 2010;138(2):e7-9.

14. Chan RCK, Chu CM, Chow C, Chan SL, Chan AWH. A concurrent primary hepatic MALT lymphoma and hepatocellular carcinoma. Pathology 2015;47(2):178-81.

15. Chatelain D, Maes C, Yzet T, et al. [Primary hepatic lymphoma of MALT-type: a tumor that can simulate a liver metastasis]. Ann Chir 2006;131(2):121-4.

16. Chen F, Ike $\mathrm{O}$, Wada $\mathrm{H}$, Hitomi S. Pulmonary mucosa-associated lymphoid tissue lymphoma 8 years after resection of the same type of lymphoma of the liver. Jpn J Thorac Cardiovasc Surg 2000;48(4):233-5. 
17. Chen Y-Y, Chen Y-F, Chen C-H. A long-term follow-up of primary hepatic mucosa-associated lymphoid tissue lymphoma. Dig Liver Dis 2020;

18. Choi S, Kim JH, Kim K, et al. Primary hepatic extranodal marginal zone lymphoma of mucosaassociated lymphoid tissue. J Pathol Transl Med 2020;54(4):340-5.

19. Doi H, Horiike N, Hiraoka A, et al. Primary hepatic marginal zone B cell lymphoma of mucosaassociated lymphoid tissue type: case report and review of the literature. Int $\mathrm{J}$ Hematol 2008;88(4):418-23.

20. Dong A, Xiao Z, Yang J, Zuo C. CT, MRI, and 18F-FDG PET/CT Findings in Untreated Pulmonary and Hepatic B-Cell Lymphoma of Mucosa-Associated Lymphoid Tissue (MALT) Over a Five-Year Period: A Case Report. Medicine (Baltimore) 2016;95(12):e3197.

21. Dong $S$, Chen L, Chen Y, Chen X. Primary hepatic extranodal marginal zone B-cell lymphoma of mucosa-associated lymphoid tissue type: A case report and literature review. Medicine (Baltimore) 2017;96(13):e6305.

22. Foschi FG, Dall'Aglio AC, Marano G, et al. Role of contrast-enhanced ultrasonography in primary hepatic lymphoma. J Ultrasound Med 2010;29(9):1353-6.

23. Francica G, Lapiccirella G. Focal liver lesions: one more example of discordance between contrastenhanced sonography and CT pattern of enhancement. AJR Am J Roentgenol 2008;190(3):W222; author reply W223.

24. Gherlan GS, Stoia R, Enyedi M, Dobrea C, Calistru PI. Primary Hepatic Marginal Zone Lymphoma in a Patient with Chronic Hepatitis C. Maedica (Buchar) 2016;11(3):250-4.

25. Gockel HR, Heidemann J, Lugering A, et al. Stable remission after administration of rituximab in a patient with primary hepatic marginal zone B-cell lymphoma. Eur J Haematol 2005;74(5):445-7.

26. Golli L, Taïeb J, Boleslawski E, et al. [Mucosa-associated lyphoid tissue hepatic lymphoma with lowgrade malignancy associated with primary biliary cirrhosis]. Gastroenterol Clin Biol 2003;27(1):1279.

27. Haefliger S, Milowich D, Sciarra A, et al. Primary hepatic marginal B cell lymphoma of mucosaassociated lymphoid tissue (MALT) and non-alcoholic steatohepatitis (NASH): more than a coincidence? Ann Hematol 2019;98(6):1513-6.

28. Hamada M, Tanaka Y, Kobayashi Y, Takeshita E, Joko K. [A case of MALT lymphoma of the liver treated by RFA and Rituximab]. Nihon Shokakibyo Gakkai Zasshi 2006;103(6):655-60.

29. Hamada T, Kakizaki S, Koiso H, Irisawa H, Nobusawa S, Mori M. Primary hepatic mucosa-associated lymphoid tissue (MALT) lymphoma. Clin J Gastroenterol 2013;6(2):150-5.

30. Igarashi T, Yokoyama Y, Ikeda T, Tsujisaki M, Yawata A. [Primary biliary cholangitis complicated by primary hepatic extranodal marginal zone lymphoma of mucosa-associated lymphoid tissue]. Rinsho Ketsueki 2019;60(11):1532-7.

31. lida T, Iwahashi M, Nakamura M, et al. Primary hepatic low-grade B-cell lymphoma of MALT-type associated with Helicobacter pylori infection. Hepatogastroenterology 2007;54(78):1898-901. 
32. Isaacson PG, Banks PM, Best PV, McLure SP, Muller-Hermelink HK, Wyatt JI. Primary low-grade hepatic B-cell lymphoma of mucosa-associated lymphoid tissue (MALT)-type. Am J Surg Pathol $1995 ; 19(5): 571-5$.

33. Ishii $\mathrm{Y}$, Tomita $\mathrm{N}$, Takasaki $\mathrm{H}$, et al. Clinical features of extranodal marginal zone lymphoma of mucosa-associated lymphoid tissue. Hematol Oncol 2012;30(4):186-9.

34. Khurana A, Mukherjee U, Patil N. An unusual case of hepatic lymphoma with multiple epithelial malignancies. Indian J Pathol Microbiol 2018;61(4):585-6.

35. Kiesewetter B, Müllauer L, Streubel B, et al. Primary mucosa-associated lymphoid tissue (MALT) lymphoma of the liver: clinical, molecular, and microbiological aspects. Ann Hematol 2012;91(11):1817-8.

36. Kikuma K, Watanabe J, Oshiro Y, et al. Etiological factors in primary hepatic B-cell lymphoma. Virchows Arch 2012;460(4):379-87.

37. Kirk CM, Lewin D, Lazarchick J. Primary hepatic B-cell lymphoma of mucosa-associated lymphoid tissue. Arch Pathol Lab Med 1999;123(8):716-9.

38. Koubaa Mahjoub W, Chaumette-Planckaert M-T, Murga Penas EM, et al. Primary hepatic lymphoma of mucosa-associated lymphoid tissue type: a case report with cytogenetic study. Int J Surg Pathol 2008;16(3):301-7.

39. Li LX, Zhou ST, Ji X, et al. Misdiagnosis of primary hepatic marginal zone B cell lymphoma of mucosa-associated lymphoid tissue type, a case report. World J Surg Oncol 2016;14:69.

40. Liu J, Guo RR, Fang JC, Zhong L. Primary hepatic mucosa-associated lymphoid tissue lymphoma with hepatocellular carcinoma: A case report and literature review. J Dig Dis 2020;

41. Lu Q, Zhang H, Wang W-P, Jin Y-J, Ji Z-B. Primary non-Hodgkin's lymphoma of the liver: sonographic and CT findings. HBPD INT 2015;14(1):75-81.

42. Maes M, Depardieu C, Dargent JL, et al. Primary low-grade B-cell lymphoma of MALT-type occurring in the liver: a study of two cases. J Hepatol 1997;27(5):922-7.

43. Mehrain S, Schima W, Ba-Ssalamah A, Kurtaran A, Raderer M. Primary MALT-lymphoma of the liver: multimodality imaging. Crit Rev Comput Tomogr 2003;44(6):347-55.

44. Mizuno S, Isaji S, Tabata M, Uemoto S, Imai H, Shiraki K. Hepatic mucosa-associated lymphoid tissue (MALT) lymphoma associated with hepatitis C. J Hepatol 2002;37(6):872-3.

45. Murakami J, Fukushima N, Ueno H, et al. Primary hepatic low-grade B-cell lymphoma of the mucosaassociated lymphoid tissue type: a case report and review of the literature. Int $\mathrm{J}$ Hematol 2002;75(1):85-90.

46. Nagata S, Harimoto N, Kajiyama K. Primary hepatic mucosa-associated lymphoid tissue lymphoma: a case report and literature review. Surg Case Rep 2015;1:87.

47. Nakayama S, Yokote T, Kobayashi K, et al. Primary hepatic MALT lymphoma associated with primary biliary cirrhosis. Leuk Res 2010;34(1):e17-20. 
48. Nart D, Ertan Y, Yilmaz F, Yüce G, Zeytunlu M, Kilic M. Primary hepatic marginal zone B-cell lymphoma of mucosa-associated lymphoid tissue type in a liver transplant patient with hepatitis $B$ cirrhosis. Transplant Proc 2005;37(10):4408-12.

49. Obiorah IE, Johnson L, Ozdemirli M. Primary mucosa-associated lymphoid tissue lymphoma of the liver: A report of two cases and review of the literature. World J Hepatol 2017;9(3):155-60.

50. Orrego M, Guo L, Reeder C, et al. Hepatic B-cell non-Hodgkin's lymphoma of MALT type in the liver explant of a patient with chronic hepatitis C infection. Liver Transpl 2005;11(7):796-9.

51. Page RD, Romaguera JE, Osborne B, et al. Primary hepatic lymphoma: favorable outcome after combination chemotherapy. Cancer 2001;92(8):2023-9.

52. Panda SS, Baisakh M, Panda A, Das H. Primary hepatic marginal zone lymphoma: A rare coincidence. Curr Probl Cancer 2018;42(3):322-8.

53. Papaxoinis G, Fountzilas G, Rontogianni D, et al. Low-grade mucosa-associated lymphoid tissue lymphoma: a retrospective analysis of 97 patients by the Hellenic Cooperative Oncology Group (HeCOG). Ann Oncol 2008;19(4):780-6.

54. Prabhu RM, Medeiros LJ, Kumar D, et al. Primary hepatic low-grade B-cell lymphoma of mucosaassociated lymphoid tissue (MALT) associated with primary biliary cirrhosis. Mod Pathol 1998;11(4):404-10.

55. Raderer M, Traub T, Formanek M, et al. Somatostatin-receptor scintigraphy for staging and follow-up of patients with extraintestinal marginal zone B-cell lymphoma of the mucosa associated lymphoid tissue (MALT)-type. Br J Cancer 2001;85(10):1462-6.

56. Raderer M, Streubel B, Woehrer S, et al. High relapse rate in patients with MALT lymphoma warrants lifelong follow-up. Clin Cancer Res 2005;11(9):3349-52.

57. Sato S, Masuda T, Oikawa H, et al. Primary hepatic lymphoma associated with primary biliary cirrhosis. Am J Gastroenterol 1999;94(6):1669-73.

58. Shin SY, Kim JS, Lim JK, Hahn JS, Yang WI, Suh CO. Longlasting remission of primary hepatic mucosa-associated lymphoid tissue (MALT) lymphoma achieved by radiotherapy alone. Korean $J$ Intern Med 2006;21(2):127-31.

59. Shiozawa K, Watanabe M, Ikehara T, et al. A case of contiguous primary hepatic marginal zone B-cell lymphoma and hemangioma ultimately diagnosed using contrast-enhanced ultrasonography. Case Rep Oncol 2015;8(1):50-6.

60. Streubel B, Lamprecht A, Dierlamm J, et al. T(14;18)(q32;q21) involving IGH and MALT1 is a frequent chromosomal aberration in MALT Iymphoma. Blood 2003;101(6):2335-9.

61. Takata N, Terasaki S, Iwata A, Harada K. [Hepatic mucosa-associated lymphoid tissue lymphoma in a patient with chronic hepatitis B]. Nihon Shokakibyo Gakkai Zasshi 2015;112(5):880-7.

62. Takeshima F, Kunisaki M, Aritomi T, et al. Hepatic mucosa-associated lymphoid tissue lymphoma and hepatocellular carcinoma in a patient with hepatitis B virus infection. $J$ Clin Gastroenterol 2004;38(9):823-6. 
63. Ueda G, Oka K, Matsumoto T, et al. Primary hepatic marginal zone B-cell lymphoma with mantle cell lymphoma phenotype. Virchows Arch 1996;428(4-5):311-4.

64. Xie H, Lv J, Ji Y, Du X, Yang X. Primary hepatic mucosa-associated lymphoid tissue lymphoma: A case report and literature review. Medicine (Baltimore) 2019;98(13):e15034.

65. Yago K, Shimada H, Itoh M, et al. Primary low-grade B-cell lymphoma of mucosa-associated lymphoid tissue (MALT)-type of the liver in a patient with hepatitis C virus infection. Leuk Lymphoma 2002;43(7):1497-500.

66. Yang X-W, Tan W-F, Yu W-L, et al. Diagnosis and surgical treatment of primary hepatic lymphoma. World J Gastroenterol 2010;16(47):6016-9.

67. Yasuda T, Nakagawa S, Imai K, et al. A case of primary hepatic mucosa-associated lymphoid tissue lymphoma incidentally found in the sustained virological response state of chronic hepatitis C: review of the literature of this rare disease. Int Cancer Conf J 2020;9(2):59-65.

68. Ye MQ, Suriawinata A, Black C, Min AD, Strauchen J, Thung SN. Primary hepatic marginal zone B-cell lymphoma of mucosa-associated lymphoid tissue type in a patient with primary biliary cirrhosis. Arch Pathol Lab Med 2000;124(4):604-8.

69. Yu Y-D, Kim D-S, Byun G-Y, et al. Primary hepatic marginal zone B cell lymphoma: a case report and review of the literature. Indian J Surg 2013;75(Suppl 1):331-6.

70. Zhong Y, Wang X, Deng M, Fang H, Xu R. Primary hepatic mucosa-associated lymphoid tissue lymphoma and hemangioma with chronic hepatitis $B$ virus infection as an underlying condition. Biosci Trends 2014;8(3):185-8.

71. Zucca E, Conconi A, Laszlo D, et al. Addition of rituximab to chlorambucil produces superior eventfree survival in the treatment of patients with extranodal marginal-zone B-cell lymphoma: 5-year analysis of the IELSG-19 Randomized Study. J Clin Oncol 2013;31(5):565-72.

72. Luppi M, Grazia Ferrari M, Bonaccorsi G, et al. Hepatitis C virus infection in subsets of neoplastic lymphoproliferations not associated with cryoglobulinemia. Leukemia 1996;10(2):351-5.

73. Silvestri F, Pipan C, Barillari G, et al. Prevalence of hepatitis C virus infection in patients with lymphoproliferative disorders. Blood 1996;87(10):4296-301.

74. Zuckerman E, Zuckerman T, Levine AM, et al. Hepatitis C virus infection in patients with B-cell nonHodgkin lymphoma. Ann Intern Med 1997;127(6):423-8.

75. Perry C, Herishanu Y, Metzer U, et al. Diagnostic accuracy of PET/CT in patients with extranodal marginal zone MALT lymphoma. Eur J Haematol 2007;79(3):205-9.

76. Luppi M, Longo G, Ferrari MG, et al. Additional neoplasms and HCV infection in low-grade lymphoma of MALT type. Br J Haematol 1996;94(2):373-5.

77. Pioltelli P, Zehender G, Monti G, Monteverde A, Galli M. HCV and non-Hodgkin lymphoma. Lancet 1996;347(9001):624-5.

78. Avlonitis VS, Linos D. Primary hepatic lymphoma: a review. Eur J Surg 1999;165(8):725-9. 
79. Liang Y, Yang Z, Zhong R. Primary biliary cirrhosis and cancer risk: a systematic review and metaanalysis. Hepatology 2012;56(4):1409-17.

80. Rodriguez J, Rawls D, Speights VO. Primary lymphoma of the liver mimicking metastatic liver disease. South Med J 1995;88(6):677-80.

81. Modi G, Madabhavi I, Patel A, et al. Primary Hepatic Burkitt Lymphoma: A Bizarre Site and Triumph Tale. J Clin Exp Hepatol 2015;5(2):159-62.

82. Colagrande S, Calistri L, Grazzini G, et al. MRI features of primary hepatic lymphoma. Abdom Radiol (NY) 2018;43(9):2277-87.

83. Claudon $M$, Cosgrove $D$, Albrecht $T$, et al. Guidelines and good clinical practice recommendations for contrast enhanced ultrasound (CEUS) - update 2008. Ultraschall Med 2008;29(1):28-44.

84. Park SH, Lee JJ, Kim HO, et al. 18F-Fluorodeoxyglucose (FDG)-positron emission tomography/computed tomography in mucosa-associated lymphoid tissue lymphoma: variation in 18F-FDG avidity according to site involvement. Leuk Lymphoma 2015;56(12):3288-94.

85. Albano D, Bosio G, Giubbini R, Bertagna F. 18F-FDG PET/CT and extragastric MALT lymphoma: role of Ki-67 score and plasmacytic differentiation. Leuk Lymphoma 2017;58(10):2328-34.

86. Weiler-Sagie M, Bushelev O, Epelbaum R, et al. (18)F-FDG avidity in lymphoma readdressed: a study of 766 patients. J Nucl Med 2010;51(1):25-30.

87. Park YK, Choi JE, Jung WY, Song SK, Lee Jl, Chung C-W. Mucosa-associated lymphoid tissue (MALT) lymphoma as an unusual cause of malignant hilar biliary stricture: a case report with literature review. World J Surg Oncol 2016;14(1):167.

88. Cheson BD, Fisher RI, Barrington SF, et al. Recommendations for initial evaluation, staging, and response assessment of Hodgkin and non-Hodgkin lymphoma: the Lugano classification. J Clin Oncol 2014;32(27):3059-68.

89. Baumhoer D, Tzankov A, Dirnhofer S, Tornillo L, Terracciano LM. Patterns of liver infiltration in lymphoproliferative disease. Histopathology 2008;53(1):81-90.

90. Isaacson PG. Mucosa-associated lymphoid tissue lymphoma. Semin Hematol 1999;36(2):139-47.

\section{Tables}

Table 1. 


\section{Summary of clinical features of reported cases of primary hepatic MALT lymphoma (including the present case).}

a

Age (y)

Sex

Male

Female

NA

Presenting symptoms

Asymptomatic

Pyrexia

Abdominal pain

Weight loss

Generalized weakness

Preexisting liver disease

HBV

$\mathrm{HCV}$

PBC

$\mathrm{AlH}$

Tumor number

Solitary

Multiple

Tumor diameter $(\mathrm{cm})$

Available MRI description

Available ultrasound scan description

Available CEUS description

Available 18F-FDG PET/CT

Mean SUV max

Misdiagnose

Hepatocellular carcinoma
Total cases $(n=110)$

63.5 (30-89) median

$42(38 \%)$

$45(41 \%)$

$23(21 \%)$

$63(57.3 \%)$

1 (0.9\%)

$7(6.4 \%)$

$2(1.8 \%)$

$3(2.7 \%)$

$21(19.1 \%)$

16 (14.5\%)

8 (7.3\%)

$2(1.8 \%)$

75 (68.2\%)

17 (15.5\%)

$3.5(0.7-20)$

35 (31.8\%)

28 (25.5\%)

6 (5.5\%)

17 (15.5\%)

4.6 (3.5-8.6)

$24(21.8 \%)$

$18(16.3 \%)$ 


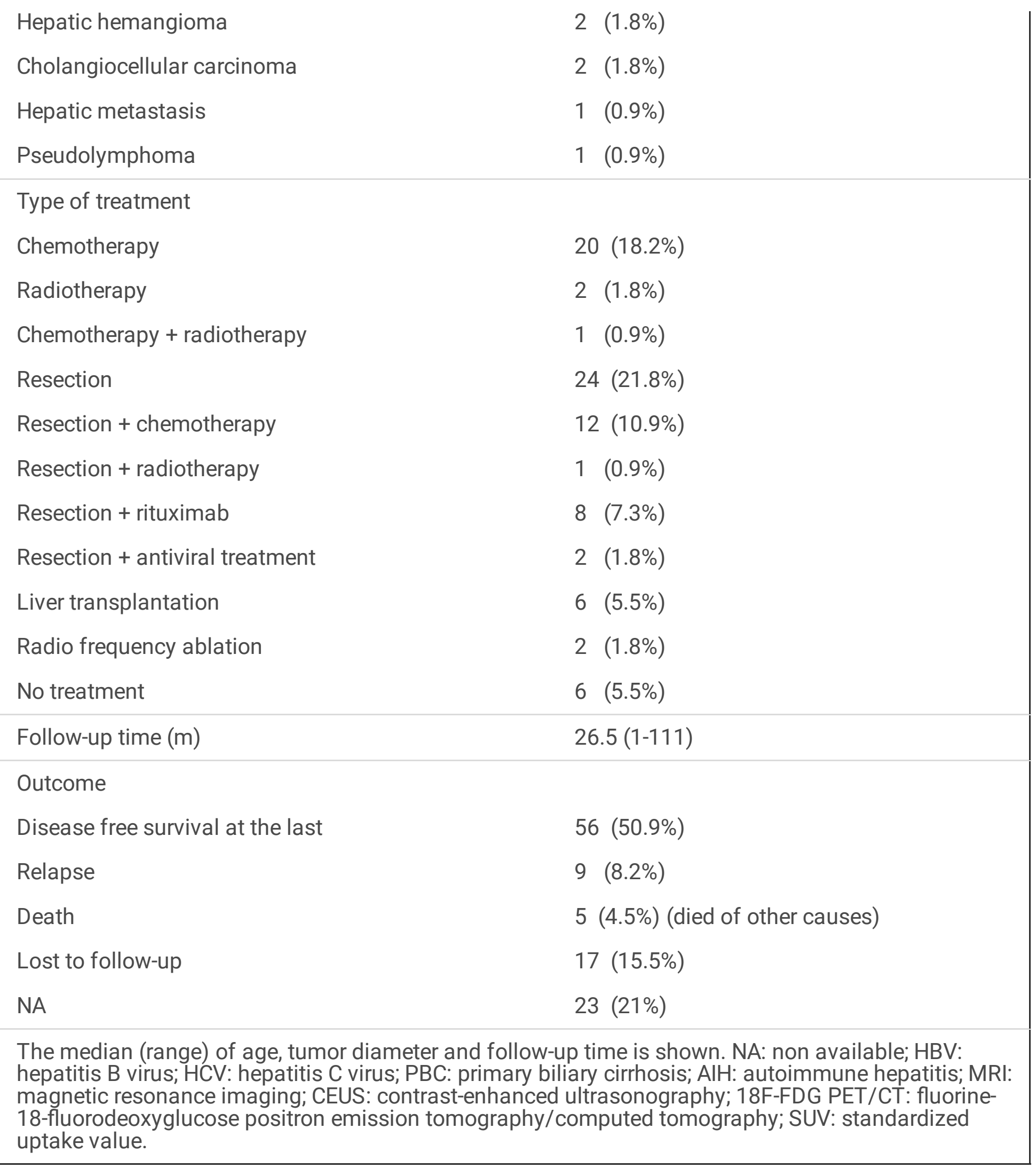

\section{Figures}



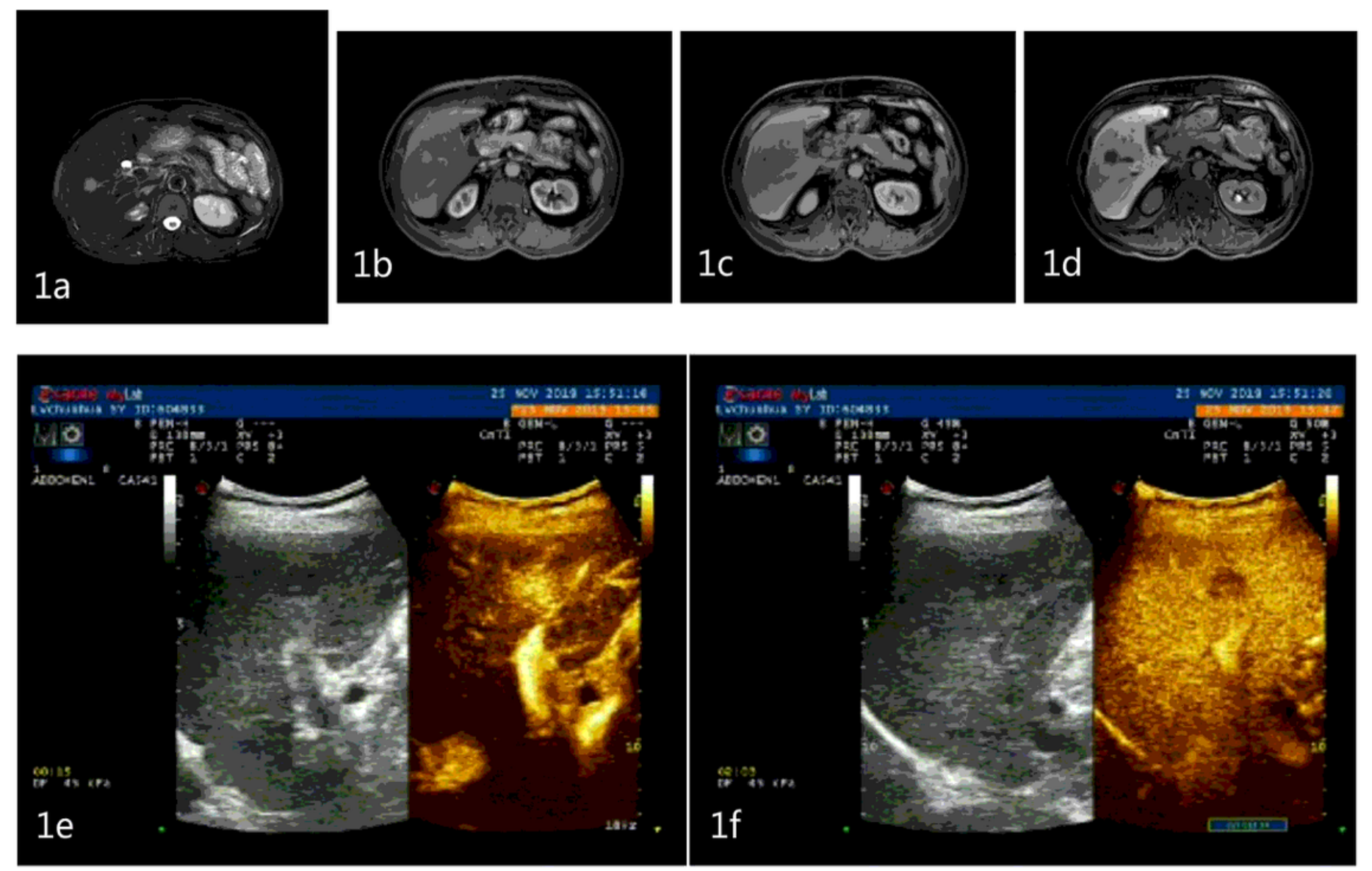

\section{Figure 1}

Enhanced magnetic resonance imaging findings were as follows: The mass was demonstrated high signal intensity on T2-weighted imaging (a). The mass was slightly enhanced in the arterial phase (b) and washed out in portal phase (c). The lesion showed low signal in hepatocyte specific phase (d). Contrast-enhanced ultrasonography showed mild inhomogeneous hyperenhancement in the arterial phase (e) and wash-out in the portal phase (f). 

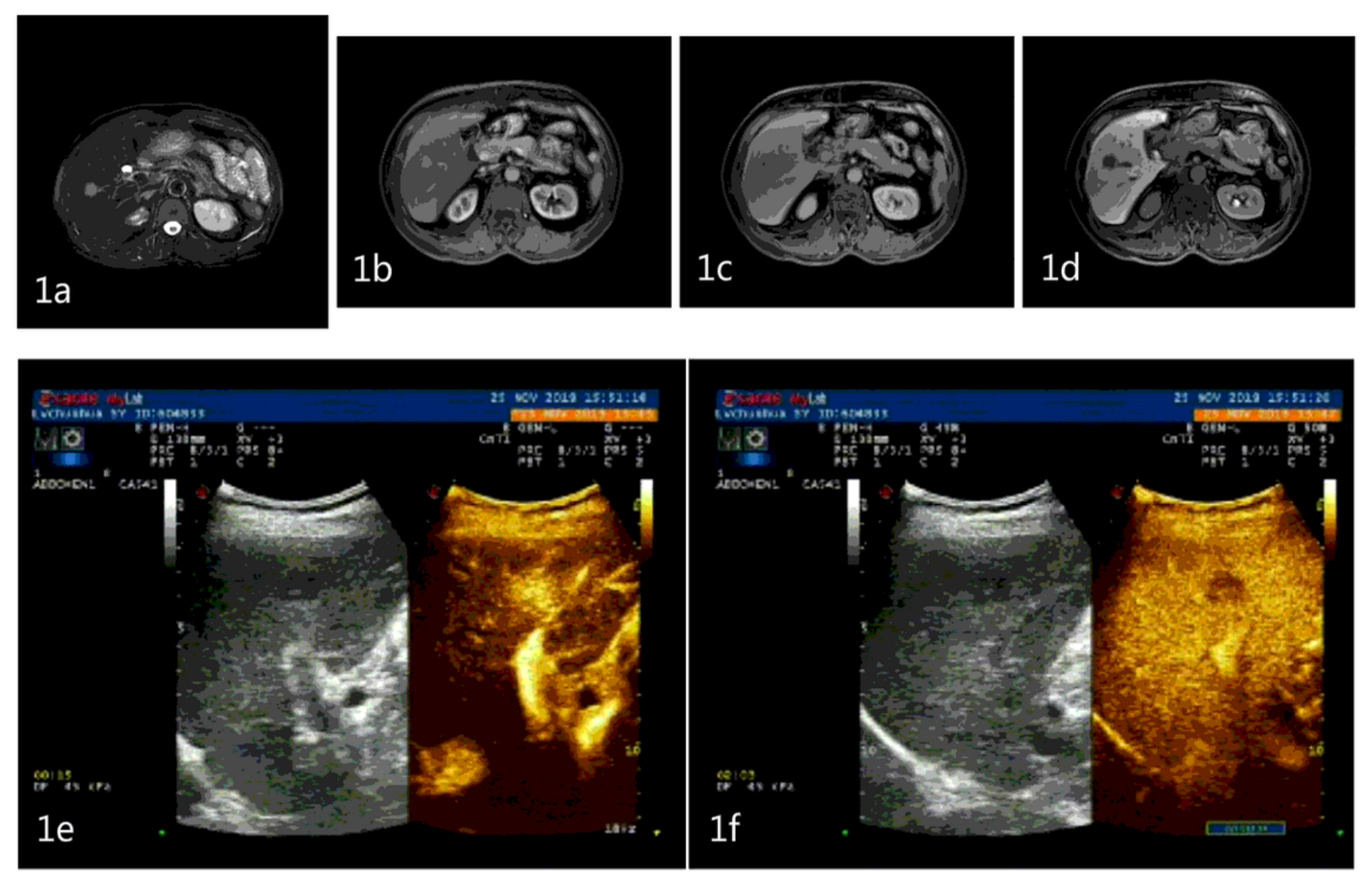

\section{Figure 1}

Enhanced magnetic resonance imaging findings were as follows: The mass was demonstrated high signal intensity on T2-weighted imaging (a). The mass was slightly enhanced in the arterial phase (b) and washed out in portal phase (c). The lesion showed low signal in hepatocyte specific phase (d). Contrast-enhanced ultrasonography showed mild inhomogeneous hyperenhancement in the arterial phase (e) and wash-out in the portal phase (f). 


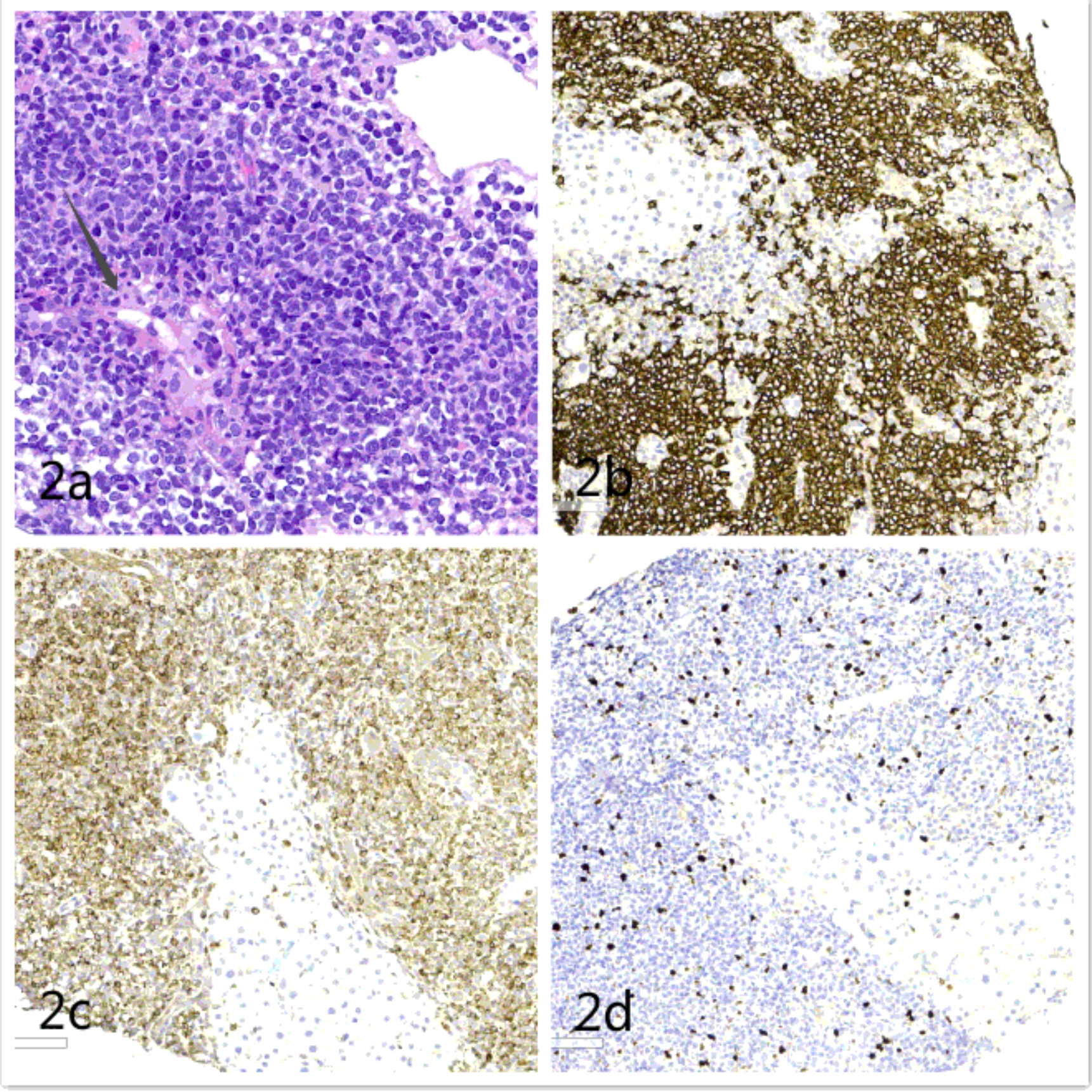

Figure 2

Characteristics of histological examination. The lesion consisted of dense lymphocyte infiltrated with lymphoepithelial lesions of bile ducts (a, the arrow, Hematoxylin and Eosin, HEx400). Lymphocytes were positive for CD20 (b) and Bcl-2 (c) antibodies. Ki-67 labeling index was about 5\% (d). 


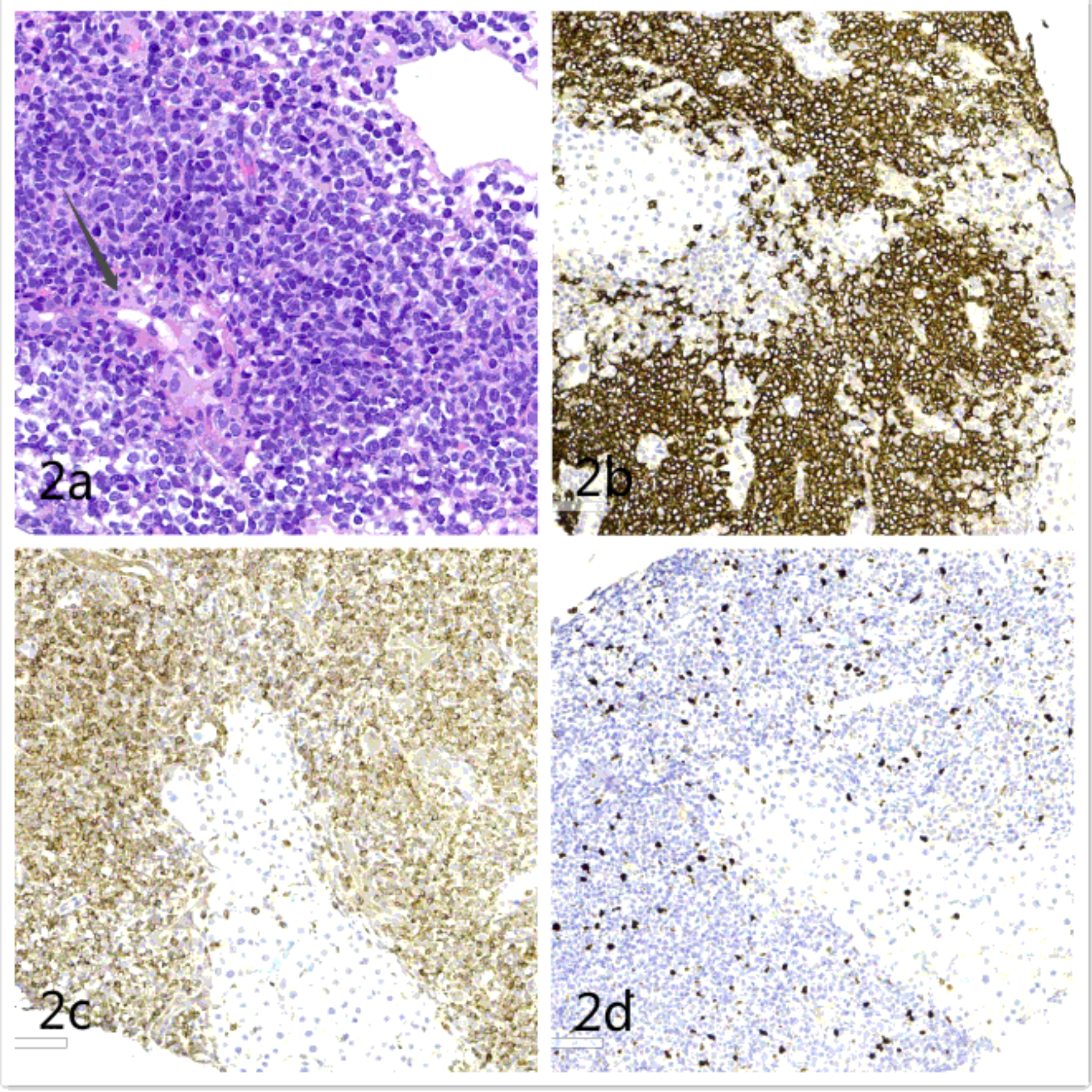

Figure 2

Characteristics of histological examination. The lesion consisted of dense lymphocyte infiltrated with lymphoepithelial lesions of bile ducts (a, the arrow, Hematoxylin and Eosin, HEx400). Lymphocytes were positive for CD20 (b) and Bcl-2 (c) antibodies. Ki-67 labeling index was about 5\% (d). 

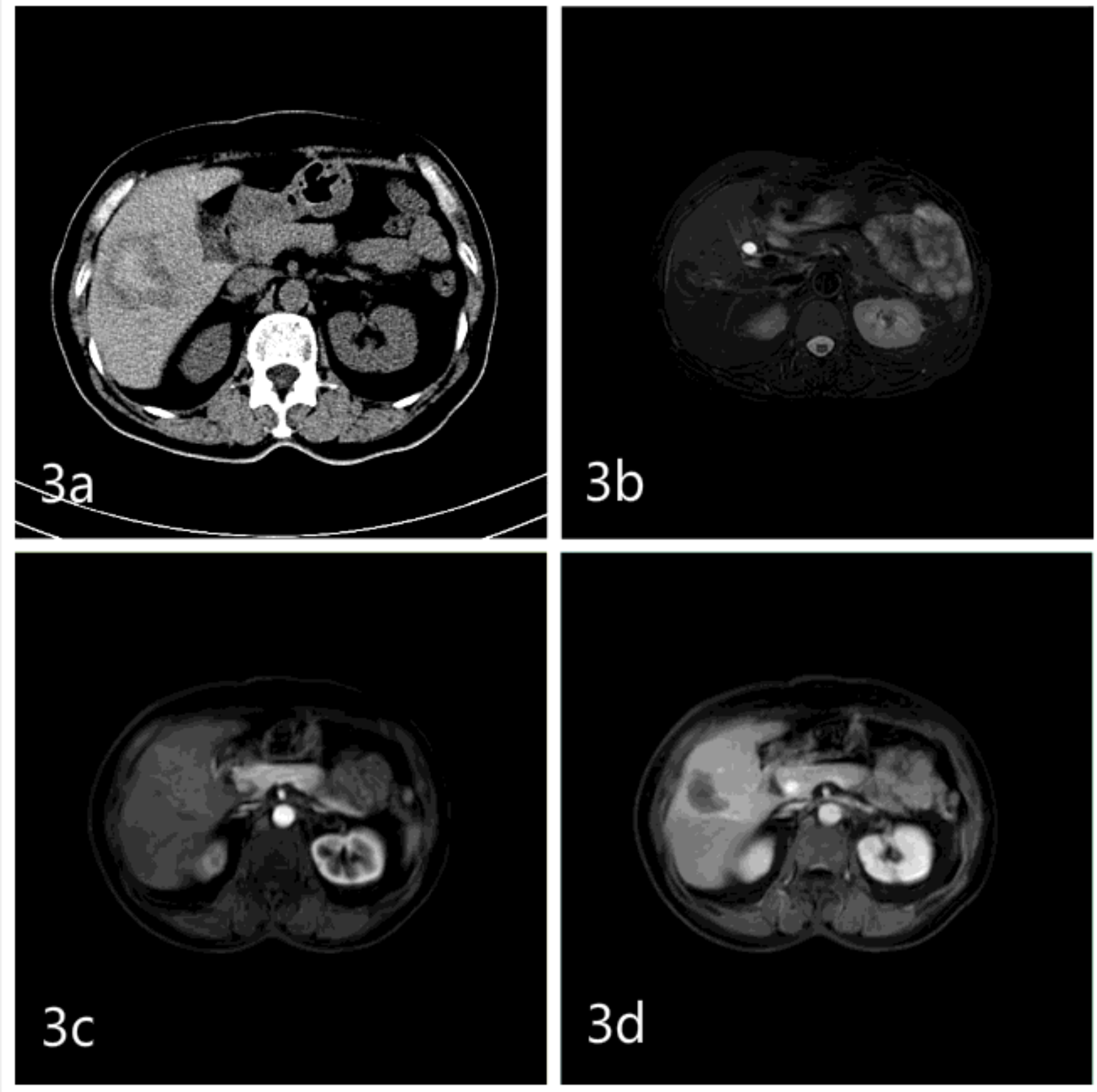

\section{Figure 3}

Computed tomography scan of the abdomen after operation showed effective results of ablation position (a). Enhanced MRI findings 12months later after RFA were as follows: No abnormal signal on T2weighted imaging (b), and there was no wash-in in the arterial phase (c) and no wash-out in portal phase (d). 

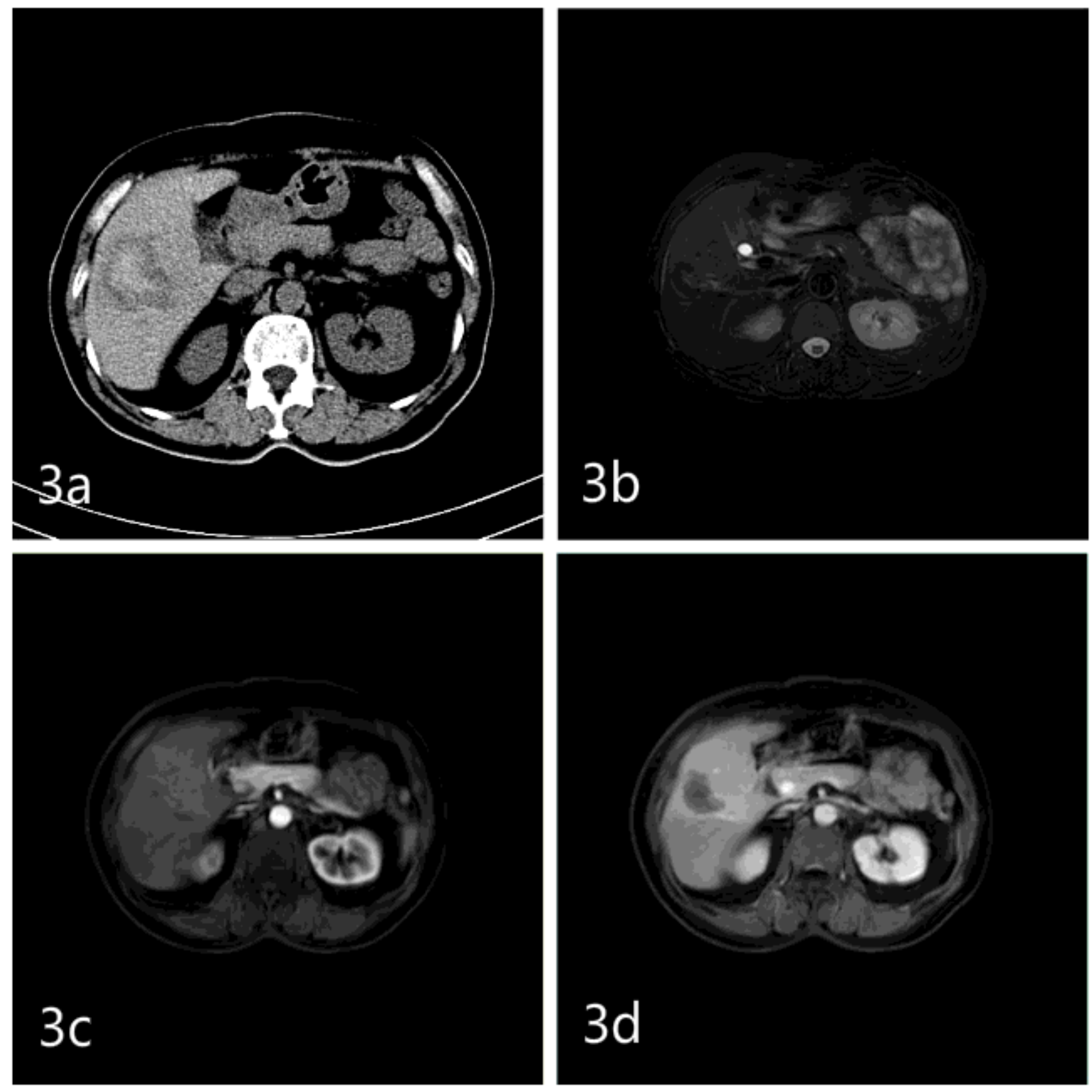

\section{Figure 3}

Computed tomography scan of the abdomen after operation showed effective results of ablation position (a). Enhanced MRI findings 12months later after RFA were as follows: No abnormal signal on T2weighted imaging (b), and there was no wash-in in the arterial phase (c) and no wash-out in portal phase (d). 